\title{
HABITAR A LINGUAGEM AO PERDER-SE PELA CIDADE
}

Anael Ribeiro Soares

Jörn Seemann deu o pontapé inicial para este enlace de poesia, fotografias e narrativa ao argumentar que "precisamos pensar em modos diferentes para apresentar as nossas ideias." Eis aqui uma experimentação que faz da diferença seu fundamento, indo de encontro às normas e estruturas acadêmicas as quais, por vezes, estamos submetidos.

Escreveu certa feita Ana Maria Hoepers Preve: "o perder-se é então o movimento necessário para produzir passagens e que se aprende nos caminhos desconhecidos do fazer alguma coisa que não se sabe aonde vai dar, mas que é preciso fazer." A essência do perder-se pela cidade mantém um diálogo íntimo com a deriva situacionista, mas também com o flanar Baudelairiano-Benjaminiano. Há, seja na deriva, seja no flanar, a necessidade de experimentar tudo aquilo que a cidade proporciona, via corporeidade, entregando-se aos processos do acaso. Mas ritmo urbano muitas vezes petrifica a eventualidade e, com isso, deixamos assim de estranhar o familiar. Por isso, subjetivamente, necessito me lançar aos tais processos do acaso, experimentar a cidade em toda sua dimensão imediata, nas paisagens, nas passagens, culminando no habitar da linguagem poética e fotográfica.

$* * *$

Vislumbro da janela do apartamento onde moro as luzes que cortam o asfalto, a sinfonia desafinada da rua, as luzes dos apartamentos que se acendem denunciando a vida dos que estão comprometidos com seus

1 Graduado em Geografia, Departamento de Geociências da Universidade Regional do Cariri (URCA). anael.rs@gmail.com.

$\gtrsim$ Rua Cel. Antônio Luiz, 1161, Pimenta, Crato, CE. 63105-000. 
respectivos afazeres. Coincidência ou não, isso logo me remete aos escritos que há pouco estava lendo: são simultaneidades de estórias-até-aqui. Ali, diante de mim, trajetórias múltiplas, confinadas naquele habitar auto-segregado. Enquanto isso, o horizonte, por trás da chapada, é banhado pela luz de uma lua ainda tímida, mas convidativa.

Às vezes, antes das errâncias, costumo observar por alguns minutos essa moldura sem igual que sempre tem algo diferente a me dizer, sussurrar. Dali, de súbito, ora no calor do dia, ora na brisa da noite, sou então acometido pelo ímpeto de ser/fazer parte da experiência da cidade, quando desejo simplesmente perambular por aí, sem rumo. Talvez isso se manifeste, precisamente, quando encontro-me completamente imerso nos tempos nulos da cotidianidade, mas pouco importa. Em geral, nunca me programo, tampouco procuro ponderar sobre o período mais propício para minhas derivas. Ao contrário dos campos que fazemos na Geografia, não tenho trajeto pré-definido porque não quero enquadrar a realidade moldando-a conforme minha expectativa. Subverto, então, aquele surrado lema do cinema novo: sigo com uma câmera na mão e nenhuma ideia na cabeça.

Saio aleatoriamente da periferia da cidade onde moro munido apenas de uma câmera fotográfica para exercer uma prática nômade no espaço estriado da cidade-aqui não convêm particularizações, basta dizer que falo duma cidade média do interior em franco processo de metropolização. Na minha deriva pelo espaço urbano, a lente de minha câmera captura aquilo que fisga meu olhar (olhar culturalmente adensado), para que depois, já no quarto, debruçado sobre as fotografias, seja feita a relação dos temas que as unem, quer dizer, quando há um tema em comum entre elas.

Neste percurso, o ato de errar pela cidade no sentido de vaguear, perambular sem rumo, do qual extraio geografias múltiplas (da vida cotidiana, da técnica, do lugar, do habitar), pode ganhar existência em formatos distintos, dentre eles, nesse caso, na poesia e nas fotografias: 
Irrompe a modernidade no céu de chumbo, e no lugar das poesias-nuvens, Impera ali a técnica: registrar, medir, quantificar e subordinar a natureza

\section{Deixar fazer}

\section{Deixar passar}

O mecanicismo cartesiano, cujo lema é cogito

Eis aí o reino do logos, onde o déspota é quem a instrumentaliza

Guiado por fins desumanos, de exploração

Mas Insuficientes ainda são as paredes

Para conter o ser-mais

Nelas, diante desse abismo-mundo,

Padecem alguns corpos emudecidos e confinados

E como ir além? Dinamitando as paredes da língua maior, já repleta de mofos?

Redimensionando o revestimento da técnica moderna?

Só a poesia liberta, há de desmoronar todo esse edifício modernista

Pois para domá-la

Nem a gramática e muito menos sua censura semântica são o bastante

Ambos, ser e poesia, extrapolam qualquer horizonte

Liberdade já a linguagem!

Habitai-vos a poesia! 


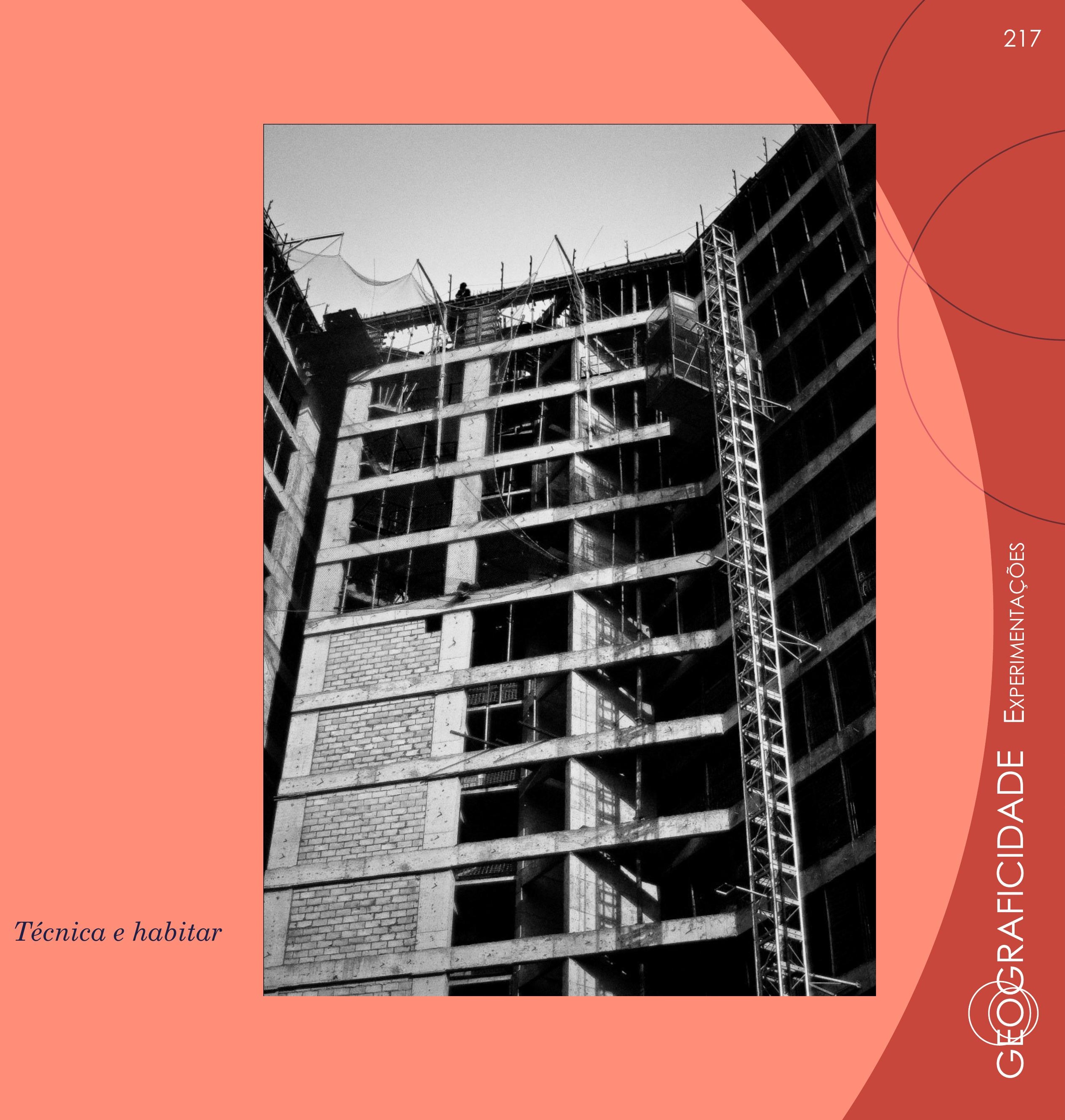




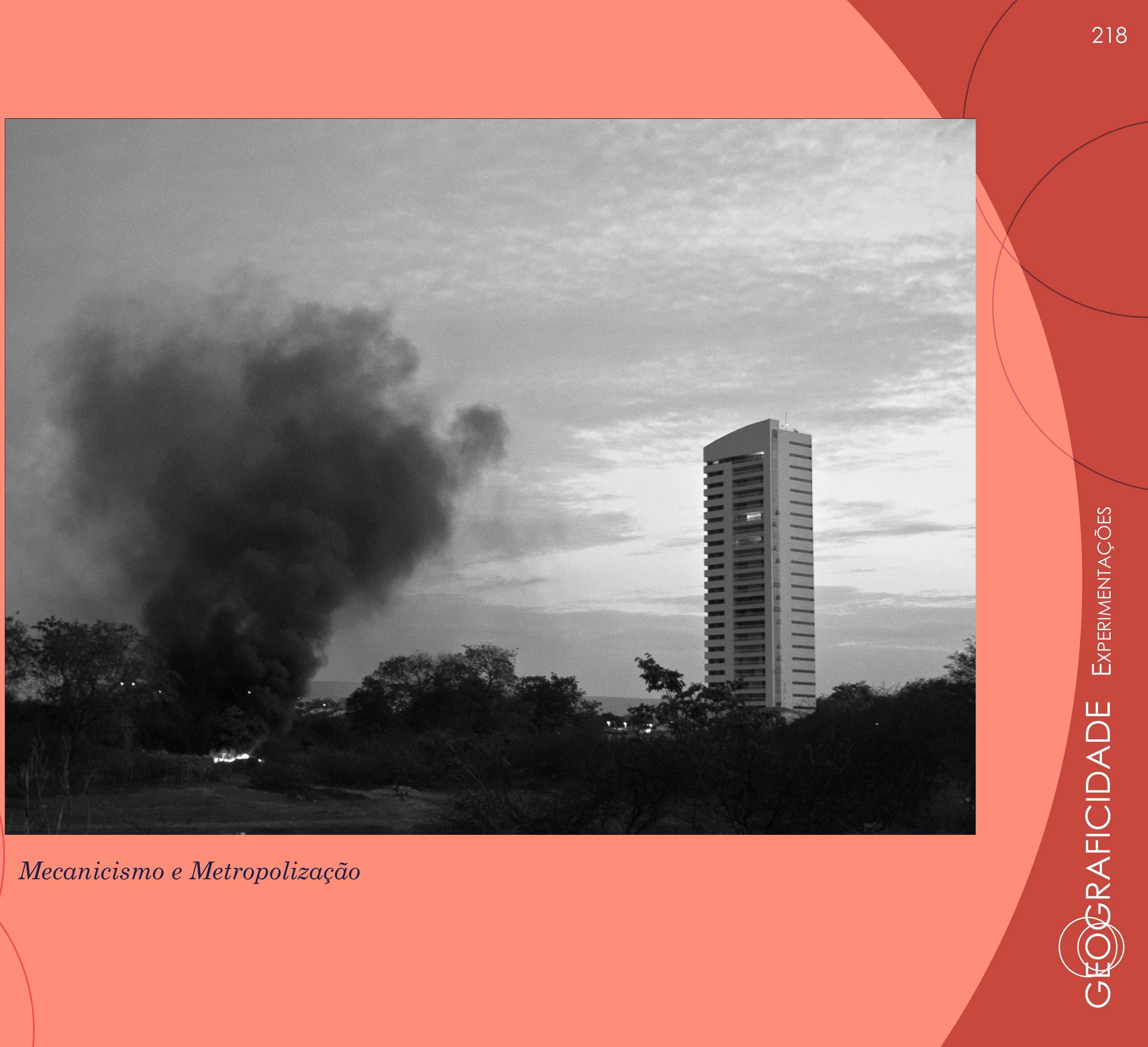




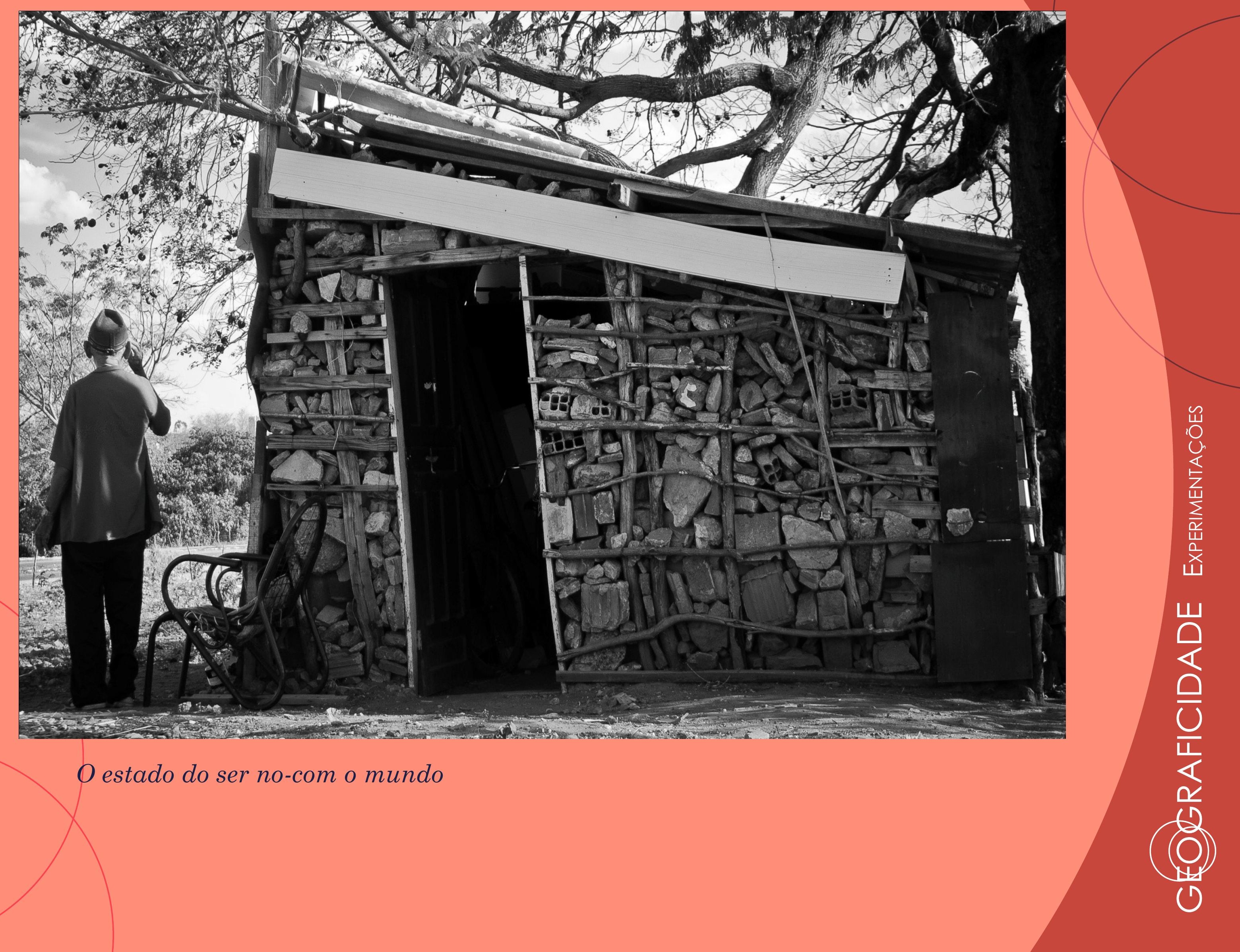

